\title{
BMJ Open Intended place of residence in old age of internal migrants aged 15-64 years: a citywide cross-sectional study in Shanghai, China
}

Jing Zhao, ${ }^{1,2}$ Yan Su, ${ }^{3}$ Yanyan Mao, ${ }^{1}$ An-na Chen, ${ }^{1}$ Xiao-ping Zhou, ${ }^{1}$ Wei-jin Zhou, ${ }^{1}$ Qian-xi Zhu ${ }^{1}$

To cite: Zhao J, Su Y, Mao Y, et al. Intended place of residence in old age of internal migrants aged $15-64$ years: a citywide cross-sectional study in Shanghai, China. BMJ Open 2019;9:e026027. doi:10.1136/ bmjopen-2018-026027

- Prepublication history for this paper is available online. To view these files please visit the journal online (http://dx.doi org/10.1136/bmjopen-2018026027).

Received 14 August 2018 Revised 24 July 2019 Accepted 26 July 2019

Check for updates

(c) Author(s) (or their employer(s)) 2019. Re-use permitted under CC BY-NC. No commercial re-use. See rights and permissions. Published by BMJ.

${ }^{1}$ Department of Reproductive Epidemiology and Social Science, NHC Key Laboratory of Reproduction Regulation (Shanghai Institute of Planned Parenthood Research), Fudan University, Shanghai, China ${ }^{2}$ Department of Cardiology, the Key Laboratory of Cardiovascular Disease, The First Hospital of Lanzhou University, Lanzhou, China ${ }^{3}$ Office of the Internal Migrants' Family Planning Services, Shanghai Municipal Commission of Health and Family Planning, Shanghai, China

Correspondence to

Dr Qian-xi Zhu;

qianxizhu@hotmail.com

\section{ABSTRACT}

Objectives To explore the intentions of working-age internal migrants concerning their place of residence in old age and the relevant influencing factors.

Method A cross-sectional survey was conducted in the 17 districts of Shanghai, China in 2013. Through multi-stage stratified sampling with probability proportional to size, 7968 internal migrants (aged 15-64 years) were selected and interviewed individually face to face. The primary outcome concerned the intended place of residence in old age of internal migrants living in Shanghai. Information was collected on demographic characteristics, health insurance, economic condition and participation in social activities. Multinomial logistic regression was performed to analyse the factors influencing migrants' intentions concerning their place of residence in old age.

Results A total of 7927 working-age migrants with complete data were analysed. Of these, $57.0 \%$ intended to live in their hometown in old age, $17.7 \%$ planned to remain in Shanghai and $25.3 \%$ were undecided. Those respondents who were male, less educated, from rural areas or Western China, living in rental houses or who had left family members behind in their hometowns were more likely to choose their hometown as their intended residence in old age $(p<0.05)$. Engagement in business, longer residence duration, possession of social insurance and participation in social activities in Shanghai were identified as possible motivators for migrants who intended to remain in Shanghai in old age $(p<0.05)$. Conclusions Most of the migrants expressed an intention to remigrate to their hometowns in old age. Education, economic capacity and social insurance influenced internal migrants in their decision. Relevant authorities should monitor the remigration pattern of ageing migrants, strengthen the senior care system and prepare health service resources that are more adequate, especially in the provinces or cities whence the migrants came.

\section{BACKGROUND}

Since the implementation of economic reforms, China has transformed from a largely agricultural country into an industrial country. Distinctive regional economic disparities have compelled farmers to migrate from the countryside to cities, particularly to
Strengths and limitations of this study

- The study focused on the intended place of residence in old age of internal migrants (aged 15-64 years) and the factors influencing that choice. Few studies have been conducted in this field in China.

- Data were obtained from a large, representative, citywide sample of working-age migrants in Shanghai. The study may reflect, to some extent, working-age migrants' current intentions concerning future remigration.

- It is difficult to interpret the causal relationship purely on the basis of the cross-sectional study. Furthermore, economic capacity, related policies and residence intentions may change.

metropolises, such as Beijing, Shanghai and Guangzhou in search of better job opportunities. ${ }^{1}$ By 2014, Shanghai had attracted about 10 million internal migrants, accounting for $47 \%$ of the city's overall resident population. ${ }^{2}{ }^{3}$ In China, the number of elderly internal migrants increased from 5.03 million in 2000 to 13.04 million in 2015 , with an average annual growth rate of $6.6 \%{ }^{4}$

In the past, China's elderly relied primarily on their adult children for care provision. This traditional family support is weakening, however, because of accelerating demographic changes caused by China's one-child policy, longer life expectancy and rural-urban migration. ${ }^{5-7}$ These issues have prompted a growing demand for alternative elderly care strategies, such as community nursing services and house-for-pension schemes. Furthermore, rapid ageing and senility in China have exacerbated healthcare and social services organisational challenges. ${ }^{56}$ Greater insight into internal migrants' perceptions of ageing in migrant cities and hometowns is needed to facilitate effective resource allocation and 
appropriate service delivery, yet few studies have explored this field in China.

Some studies conducted in Western countries have investigated the factors influencing migration among the elderly. ${ }^{8-11}$ Demographic characteristics (age, sex); health status; socioeconomic characteristics and financial resources (income, home ownership, housing conditions); family structure; personal ties and satisfaction within the community play crucial roles in shaping the migration patterns of the elderly. ${ }^{12-19}$ Moreover, local policies, availability of satisfactory medical care and social welfare; local cost of living and local climate have been found to be significantly associated with elderly migration. ${ }^{12} 151618$ However, few studies have explored working-age migrants' intentions concerning their place of residence in old age. ${ }^{80}$ One study of migrants' perceptions of ageing, conducted in Denmark, was based on a qualitative analysis that involved only 22 participants. ${ }^{20}$

In this study, we conducted a citywide cross-sectional survey of working-age internal migrants settled in Shanghai to determine their residence intentions in old age, with an emphasis on identifying the factors shaping their perceptions, including demographic characteristics, hukou (a system of household registration used in mainland China), health insurance, housing conditions and participation in social activities.

\section{METHODS}

\section{Study design}

This cross-sectional survey was conducted in the 17 districts of Shanghai in 2013. Individuals between 15 and 64 years of age were considered eligible for participation if they were internal migrants from other regions of China and had resided in Shanghai for at least 1 month. Participation was restricted to those who, along with their spouses, were unregistered in Shanghai's hukou system. A total of 7968 migrants were selected through multi-stage stratified sampling with probability proportional to size based on the migrant populations of the 17 districts. Informed consent was obtained prior to the initiation of individual interviews. Well-trained investigators conducted face-toface interviews using structured questionnaires. Of the 7968 subjects, 41 were excluded from the analysis because of missing data on age (seven cases), monthly income (22 cases) or occupation (12 cases). Data from 7927 participants $(99.5 \%)$ were analysed.

\section{Measurement}

In the investigation, the primary outcome was related to where the migrants wished to live during their old age, with three options: 'stay in Shanghai', 'remigrate to hometown' and 'undecided'. The questionnaire included questions on demographics, occupation, financial and social insurance status, housing conditions, family type and social engagement. Occupation was categorised into four groups: 'service worker', 'skilled worker', 'businessperson' and 'unemployed'. Education attainment was classified as 'less than high school education', 'high school or vocational education' and 'college degree and above'. Family type was categorised as 'living with all members of core family in Shanghai', 'at least one family member left behind in hometown' and 'unmarried'. Hukou was classified as 'rural hukou' and 'urban hukou'. The locations of the migrants' hometowns were classified as 'Eastern China', 'Central China', 'Northeast China' and 'Western China', the four economic regions of China, according to the socioeconomic development of the regions. ${ }^{21}$ Health insurance was grouped into three categorises: 'covered in hometown only', 'covered in Shanghai (including those migrants with health insurance in their hometowns)' and 'uncovered'. Coverage by the Housing Provident Fund in Shanghai was grouped under 'uncovered' and 'covered'. Housing condition was classified under 'rental housing', 'low-income housing' and 'commercial-residential housing'. The term 'low-income housing' refers to economically affordable houses for lower income families; this is usually subsidised by the local government or a worker's employer. Duration of residence in Shanghai was determined by asking the respondents how many years they had been in Shanghai. Participation in social activities in the community was categorised under 'no activity' and 'at least once'.

\section{Statistical methods}

Statistical analysis was performed using STATA V.14 (StataCorp LP). First, we determined the distribution of characteristics of subjects based on their residence intentions in old age. We then performed multinomial logistic regression to examine the significance of the factors associated with their intentions. We included 13 variables identified on the basis of our qualitative interview study, previous studies and the context of China. In model 1 , taking the migrants who planned to remigrate to their hometowns as the reference group, we examined the ORs of relevant factors, comparing the 'stay in Shanghai' group with the 'remigrate to hometown' group and then 'undecided' group with the'remigrate to hometown' group. In model 2, we examined differences between the 'stay in Shanghai' group and the 'undecided' group. A two-sided $\mathrm{p}$ value less than 0.05 was considered statistically significant.

\section{Patient and public involvement}

Patients and members of the public were not involved in the development of the research questions, recruitment, design or conduct of the study. The results will be disseminated to patients and the public through this publication.

\section{RESULTS}

Of the 7927 migrants, 1408 (17.7\%) expressed the intention to stay in Shanghai in their old age, $4516(57.0 \%)$ intended to remigrate to their hometowns, and 2003 (25.3\%) were undecided. In the 15-29 and 30-39 age groups, the proportions of intended place of residence 
were similar, and the combined percentages were $54.9 \%$ for hometown, $18.0 \%$ for Shanghai and $27.1 \%$ for undecided. However, in the $\geq 40$ age group, the corresponding percentages were $63.4 \%, 17.1 \%$ and $19.5 \%$, respectively. The percentages choosing Shanghai were similar, but more migrants had decided to remigrate to their hometown, meaning there were fewer who were undecided.

As previously stated, the migrants were between 15 and 64 years of age (mean \pm SD: $33.3 \pm 8.9$ ), with about half of them being male $(51.1 \%)$. The migrants were principally from rural areas $(77.3 \%)$ and central China $(51.3 \%)$. Most had completed junior high school or lower education $(61.4 \%)$, and about $65 \%$ were service workers. Monthly incomes of the migrants ranged from $¥ 2500$ (25th percentile) to $¥ 5000$ ( 75 th percentile), with the median at $¥ 3000$. Table 1 summarises the migrants’ characteristics based on their migration intentions concerning place of residence in old age (hometown, Shanghai, undecided).

Table 2 presents the ORs of migrants who intended to stay in Shanghai and those who were undecided compared with those who intended to remigrate to their hometowns (model 1). Table 2 also presents the ORs of migrants who intended to stay in Shanghai, compared with those who were undecided (model 2).

\section{Shanghai versus hometown and undecided versus hometown}

In model 1, taking the group of migrants who intend to return to their hometowns in old age as the control group, the ORs for the group of migrants who had chosen to stay in Shanghai and the ORs for the group of migrants who were undecided were similar and statistically significant for most of the selected factors. Model 1 showed that the male gender, rural hukou and lower education were associated with an increased intention to remigrate to one's hometown in one's advanced years. Migrants from Western China were more likely to choose their hometown as their place of residence in old age than were those from Eastern China, Central China or Northeast China. Compared with migrants who owned low-income housing or commercial-residential housing, those who rented apartments exhibited a higher likelihood of intending to remigrate to their hometown. Migrants who were covered by health insurance in their hometown but not in Shanghai and those who were not covered by the Housing Provident Fund were more likely to choose to age in their hometowns. Shorter duration of residence and non-participation in social activities in Shanghai were associated with an increased likelihood of intending to spend one's old age in one's hometown. Compared with those living with all core family members in Shanghai, those who had left at least one family member behind in their hometown had an increased likelihood of remigration intention. However, there were some inconsistent ORs between the two sets of comparison groups. When compared with service workers, businesspeople were more likely to choose to stay in Shanghai than to remigrate to their hometown. Such a correlation was not found in the undecided group when compared with the group intending to remigrate.

\section{Shanghai versus undecided}

Model 2 showed that higher education level, coverage by medical insurance in Shanghai, ownership of commercial-residential housing and longer duration of residence in Shanghai were associated with an increased intention to choose Shanghai as the future place of residence. Businesspeople and skilled workers (when compared with service workers) and migrants without family members left behind in hometowns (when compared with those who had left at least one family member behind in their hometowns) were more likely to express the intention to stay in Shanghai.

\section{DISCUSSION}

Among working-age migrants, the proportion of those who intended to remigrate in their old age $(57.0 \%)$ was about three times the proportion of migrants who wished to spend their elderly years in Shanghai $(17.7 \%)$. In the older age group ( $\geq 40$ years), there was a decrease in the number of undecided migrants, and more migrants chose their hometowns. The high proportion of migrants who plan to go back to their hometowns will pose an enormous challenge to the State in terms of ensuring a sustainable social welfare and health system. Because official sources of funding for welfare programme are meagre, the private sector is being encouraged to invest in the senior care industry to deal with the pressure of an ever-growing population of elderly migrants. ${ }^{22}{ }^{23}$ It is urgent that wider sources of support be found for places where ageing is taking place, especially for migrants' hometowns with large outflow populations.

In our study, sex, education, occupation, hukou classification, location of hometown, health insurance, housing provident fund, housing condition, duration of residence in Shanghai, left-behind family members and participation in social activities were associated with internal migrants' perceptions of residence locations in old age. Although the study outcome concerns the future intentions of working-age migrants, the results related to the associated factors were supported by some studies on migration patterns among the elderly. ${ }^{12-15}$

In China, internal migrants are defined as those who live outside their cities of hukou registration. Hukou, a permanent household registration system, ties citizens' access to services according to their hukou location and hukou classification (rural vs urban). Many public policies and social welfare systems in China are implemented on the basis of the hukou system, and urbanrural and interprovincial differentials are considerable. On the other hand, China is characterised by substantial regional diversity in terms of culture, social conventions, dialects and climates. Western China is more different from Shanghai than Eastern China in terms of culture and climate. ${ }^{24}$ Some prior studies in Western countries 
Table 1 Migrant characteristics based on migration intentions concerning place of residence in old age

\begin{tabular}{llll} 
N (\%) & & & \\
\hline All & Hometown & Shanghai & Undecided \\
\hline 7927 & $4516(57.0)$ & $1408(17.7)$ & $2003(25.3)$
\end{tabular}

Age (years)

$\begin{array}{lllll}15-29 & 3199(40.4) & 1777(39.3) & 497(35.3) & 925(46.2) \\ 30-39 & 2813(35.5) & 1524(33.8) & 584(41.5) & 705(35.2) \\ 40+ & 1915(24.2) & 1215(26.9) & 327(23.2) & 373(18.6)\end{array}$

Sex

$\begin{array}{llllr}\text { Male } & 4048(51.1) & 2381(52.7) & 684(48.6) & 983(49.1) \\ \text { Female } & 3879(48.9) & 2135(47.3) & 724(51.4) & 1020(50.9) \\ \text { Occupation } & & & & \end{array}$

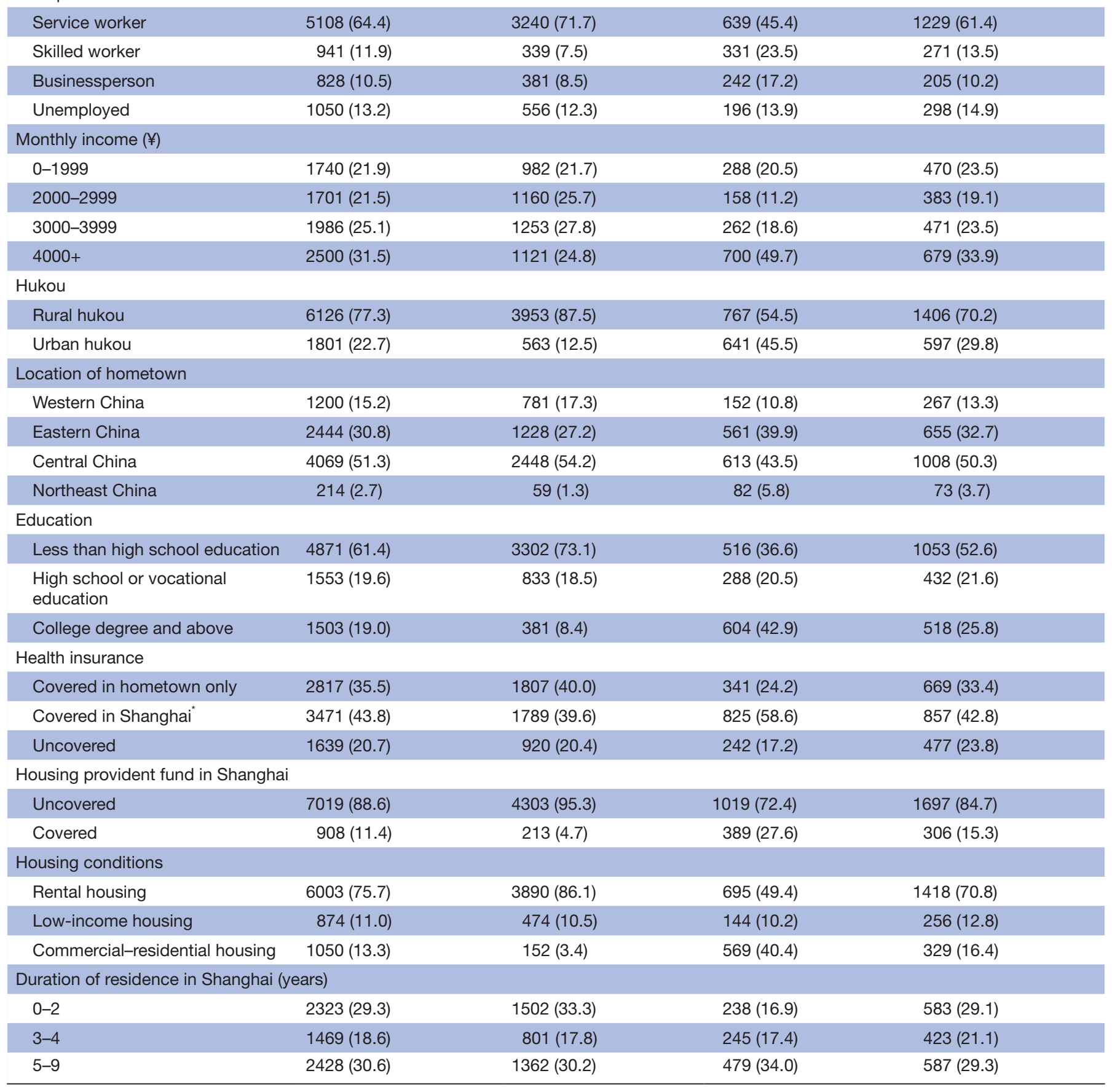




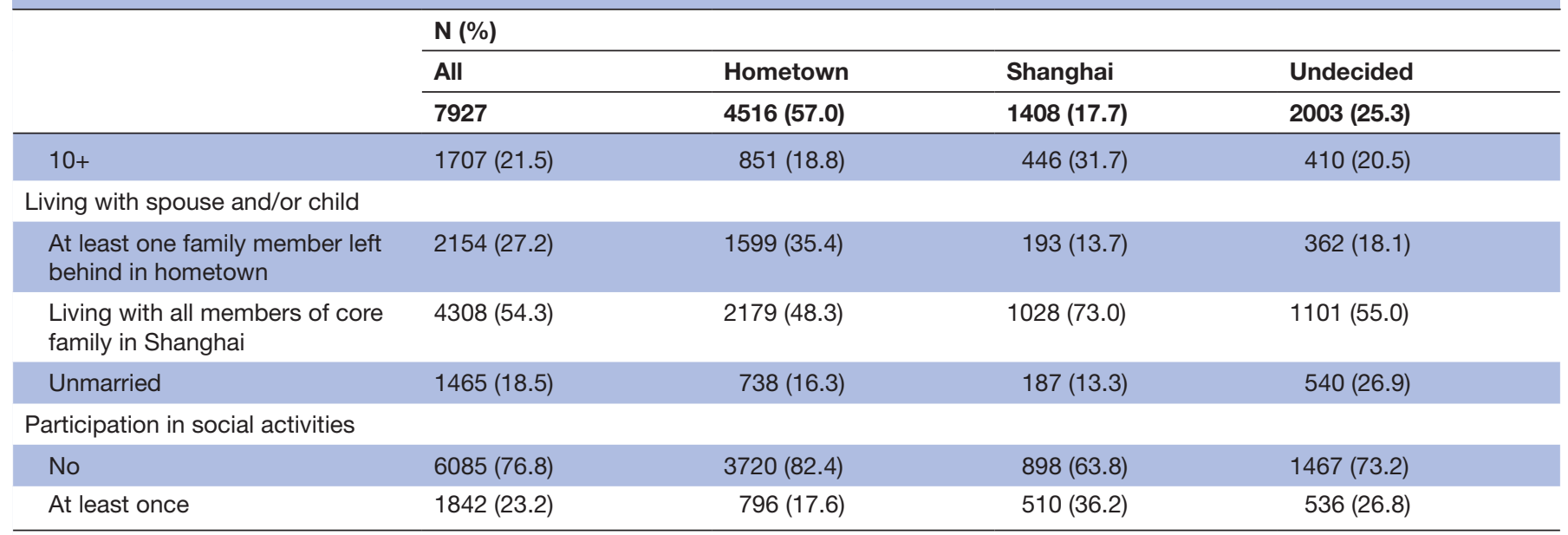

*Includes those migrants with health insurance in their hometowns.

provide evidence that climate plays a role in shaping retirement migration decisions, although Dou's study did not show such an association. ${ }^{12} 1618$ With respect to ageing in Shanghai, rural migrants will confront more difficulties in terms of both spiritual adaptation and material cost of living. ${ }^{25}$ Thus, both urban-rural classification and location of hukou influenced the migrants' future intentions.

Education level is related to jobs and economic capacity and to the accessibility of local health services and aged care provision, as well as to educational opportunities for children. ${ }^{162627}$ In our study, advanced education was found to be positively associated with migrants' intentions to stay in Shanghai, suggesting direct and indirect effects of education on internal migration.

Participation in health insurance increases the likelihood of migrants' intentions being to stay in Shanghai. This observation is supported by previous studies, which identified accessible health services as a major consideration in decisions regarding where to live in old age. ${ }^{9} 2028$ Although China's government is devoted to improving the cross-regional transfer of health insurance accounts, large disparities among regions, a lack of resource allocation and the hukou system create huge challenges on this issue. ${ }^{2-31}$ Health insurance cannot be drawn on in its entirety when migrants leave Shanghai. On the other hand, migrants who are only covered by health insurance in their hometowns have limited access to reimbursable health services in Shanghai. ${ }^{32}$ This limitation induces the intention to return to one's hometown in old age.

Our findings support the results of many prior studies that home ownership and housing conditions are key factors influencing older migrants' mobility. ${ }^{12} 1617$ The majority of the Chinese regard home ownership as the symbol of a genuine settler. Therefore, for migrants who owned a house in Shanghai, the likelihood of intending to age in Shanghai was significantly elevated. Housing prices in Shanghai are much higher than in second-tier cities, let alone counties or villages. This may partially explain why the likelihood of planning to stay in Shanghai was higher for businesspeople than for service workers, with businesspeople being better off financially. However, monthly income was not a significant factor for remigration. We speculate that the effect of income may be moderated by the effects of education, occupation and home ownership.

Male subjects were more likely than female subjects to choose their hometown as their place of residence in old age. In China, traditional concepts of filial piety, under which men are responsible for the care and support of their families, are widely held. Given the much higher cost of living in Shanghai, this responsibility would increase the likelihood that male migrants will feel compelled to remigrate to their hometowns in old age. Furthermore, left-behind family members in hometowns may increase migrants' desire to return. This finding is consistent with previous work demonstrating the significant association of these family members with migrants' remigration motives. $^{14172833}$

Our results also imply that duration of residence, rather than age, influences migrants' intentions. As the duration of residence increases, migrants become progressively familiar with the city and alienated from their hometowns. ${ }^{20}$ In addition, participation in social activities can facilitate the establishment of social networks for migrants and reduce social isolation. ${ }^{193435}$ Kristiansen showed that migrants who had established social lives in Denmark experienced deeper feelings of belonging and were more likely to stay there in old age. ${ }^{20}$ Norredam showed that migrants would choose to remigrate if they were unable to integrate well into a new community. ${ }^{36}$

Our study explores working-age migrants' intentions concerning place of residence in old age in China. We obtained a large, citywide, representative sample of working-age migrants in Shanghai. The distributions of some characteristics (eg, sex, age and hometown) are similar to those of the migrants registered in the 2013 Shanghai census. This study offers new insights into the ageing problem of internal migrants in Shanghai. In addition, 
Table 2 Multinomial logistic regression results on options for place of residence in old age among internal migrants $(n=7927)$

Model 1

Model 2

\begin{tabular}{|c|c|c|c|}
\hline Shanghai versus hometown & $\begin{array}{l}\text { Undecided versus } \\
\text { hometown }\end{array}$ & & Iue \\
\hline OR (95\% Cl) & OR $(95 \% \mathrm{Cl})$ & $P$ value & OR $(95 \% \mathrm{Cl})$ \\
\hline
\end{tabular}

Age (years) 15-29 1

30-39

$40+$ $0.96(0.80$ to 1.15$) \quad 0.663$

1

1

Sex

1.06 (0.85 to 1.32$) \quad 0.610$

1.05 (0.90 to 1.22)

$0.521 \quad 0.91(0.75$ to 1.10$)$

0.332

Male

1

0.85 (0.71 to 1.02$)$

0.0791 .24 (0.98 to 1.57 )

0.070

Female

$1.28(1.10$ to 1.49$) \quad 0.002$

1

1

Occupation

\begin{tabular}{|c|c|c|c|c|c|c|}
\hline Service worker & 1 & & 1 & & 1 & \\
\hline Skilled worker & 1.21 (0.96 to 1.52$)$ & 0.110 & 0.91 (0.73 to 1.12$)$ & 0.359 & 1.33 (1.06 to 1.66$)$ & 0.012 \\
\hline Businessperson & 1.74 (1.40 to 2.17$)$ & $<0.001$ & $1.06(0.86$ to 1.29$)$ & 0.588 & 1.65 (1.31 to 2.08 ) & $<0.001$ \\
\hline \multicolumn{7}{|l|}{ Monthly income (¥) } \\
\hline 0-1999 & 1 & & 1 & & 1 & \\
\hline 3000-3999 & 0.96 (0.72 to 1.28$)$ & 0.777 & 0.93 (0.75 to 1.16$)$ & 0.537 & $1.03(0.75$ to 1.40$)$ & 0.863 \\
\hline $4000+$ & $1.09(0.82$ to 1.46$)$ & 0.548 & 1.01 (0.81 to 1.27$)$ & 0.910 & 1.08 (0.79 to 1.47$)$ & 0.632 \\
\hline \multicolumn{7}{|l|}{ Hukou } \\
\hline Rural hukou & 1 & & 1 & & 1 & \\
\hline Urban hukou & 1.31 (1.08 to 1.60$)$ & 0.007 & 1.42 (1.20 to 1.68$)$ & $<0.001$ & 0.92 (0.76 to 1.13$)$ & 0.433 \\
\hline Eastern China & 1.37 (1.09 to 1.72$)$ & 0.007 & 1.28 (1.07 to 1.53$)$ & 0.008 & 1.07 (0.84 to 1.37$)$ & 0.576 \\
\hline Central China & $1.26(1.01$ to 1.57$)$ & 0.037 & $1.23(1.04$ to 1.45$)$ & 0.015 & 1.03 (0.81 to 1.30$)$ & 0.827 \\
\hline Northeastern China & 2.20 (1.40 to 3.46$)$ & 0.001 & 1.87 (1.24 to 2.81$)$ & 0.003 & 1.18 (0.79 to 1.76$)$ & 0.426 \\
\hline \multicolumn{7}{|l|}{ Education } \\
\hline $\begin{array}{l}\text { Less than high school } \\
\text { education }\end{array}$ & 1 & & 1 & & 1 & \\
\hline High school education & 1.67 (1.38 to 2.02$)$ & $<0.001$ & 1.26 (1.08 to 1.46$)$ & 0.003 & 1.33 (1.08 to 1.63$)$ & 0.006 \\
\hline College degree and above & 3.05 (2.37 to 3.93$)$ & $<0.001$ & 1.85 (1.49 to 2.31$)$ & $<0.001$ & 1.64 (1.28 to 2.11$)$ & $<0.001$ \\
\hline \multicolumn{7}{|l|}{ Health insurance } \\
\hline
\end{tabular}

Housing provident fund in

Shanghai

\begin{tabular}{|c|c|c|c|c|c|c|}
\hline Uncovered & 1 & & 1 & 1 & 1 & \\
\hline Covered & 1.59 (1.24 to 2.05$)$ & $<0.001$ & 1.55 (1.22 to 1.96$)$ & $<0.001$ & 1.03 (0.82 to 1.30$)$ & 0.801 \\
\hline \multicolumn{7}{|l|}{ Housing conditions } \\
\hline Rental housing & 1 & & 1 & & 1 & \\
\hline Low-income housing & 1.37 (1.11 to 1.70$)$ & 0.004 & 1.33 (1.12 to 1.58$)$ & 0.001 & 1.03 (0.82 to 1.30$)$ & 0.776 \\
\hline $\begin{array}{l}\text { Commercial-residential } \\
\text { housing }\end{array}$ & 6.01 (4.79 to 7.53$)$ & $<0.001$ & 3.25 (2.60 to 4.08$)$ & $<0.001$ & 1.84 (1.51 to 2.25$)$ & $<0.001$ \\
\hline
\end{tabular}

Continued 


\begin{tabular}{|c|c|c|c|c|c|c|}
\hline & \multicolumn{4}{|l|}{ Model 1} & \multirow{2}{*}{\multicolumn{2}{|c|}{$\begin{array}{l}\text { Model } 2 \\
\text { Shanghai versus undecided }\end{array}$}} \\
\hline & \multicolumn{2}{|c|}{ Shanghai versus hometown } & \multicolumn{2}{|l|}{$\begin{array}{l}\text { Undecided versus } \\
\text { hometown }\end{array}$} & & \\
\hline \multicolumn{7}{|l|}{$\begin{array}{l}\text { Duration of residence in } \\
\text { Shanghai (years) }\end{array}$} \\
\hline $5-9$ & 1.55 (1.27 to 1.91$)$ & $<0.001$ & $1.23(1.05$ to 1.44$)$ & 0.009 & 1.27 (1.02 to 1.57$)$ & 0.031 \\
\hline $10+$ & $2.79(2.24$ to 3.48$)$ & $<0.001$ & $1.52(1.27$ to 1.82$)$ & $<0.001$ & $1.83(1.45$ to 2.31$)$ & $<0.001$ \\
\hline \multicolumn{7}{|l|}{ Living with spouse and/or child } \\
\hline $\begin{array}{l}\text { At least one family member } \\
\text { left behind in hometown }\end{array}$ & 1 & & 1 & & 1 & \\
\hline Unmarried & 2.06 (1.58 to 2.70$)$ & $<0.001$ & 3.02 (2.49 to 3.67 ) & $<0.001$ & 0.68 (0.52 to 0.90$)$ & 0.008 \\
\hline \multicolumn{7}{|l|}{ Participation in social activities } \\
\hline No & 1 & & 1 & & 1 & \\
\hline At least once & $1.46(1.25$ to 1.71$)$ & $<0.001$ & $1.33(1.16$ to 1.53$)$ & 0.001 & 1.09 (0.93 to 1.28$)$ & 0.265 \\
\hline
\end{tabular}

*Includes those migrants having health insurance in their hometowns.

the structured questionnaire, uniformly trained investigators and face-to-face interviews ensured the collection of high-quality and comprehensive data. The questionnaire contained comprehensive questions, and the results, to some extent, reflect the thoughts of working-age migrants. Further research is needed to follow-up these migrants, to acquire a better understanding of remigration patterns and to predict the need for social services and medical resources in different regions.

\section{Limitations of this study}

Our study investigated only the options of staying in Shanghai, returning to one's hometown and indecision without considering specific hometowns or other options. For the 'hometown' choice, it was difficult to accurately represent the different locations of migrants' hometowns. In addition, the study administered a cross-sectional survey, which presented difficulties for the interpretation of the causal relationship between migrants' characteristics and their future intentions. Moreover, the findings on residence intentions in old age reflected only the migrants' current opinions on ageing, which are changeable, especially for those migrants younger than 30 years of age.

\section{CONCLUSIONS}

The results of the study showed that the majority of the migrants expressed an intention to remigrate to their hometowns in old age. Education, economic capacity and social insurance influenced internal migrants in their intentions. Healthcare facilities and welfare systems should therefore be improved to satisfy the considerable needs of ageing migrants, particularly in the areas whence they came. Given that perceptions regarding ageing among migrants may change over time, a follow-up study is needed to determine their final plans for ageing.

AcknowledgmentsWe greatly appreciate the excellent assistance provided by Hong Huang, Mei-xing Zhang, Lan-lan Cai, Xue Yang, Zhi-qi Qu and the Shanghai Municipal Commission of Health and Family Planning. Special thanks also go to each of the district-level branches of the Commission, which fully supported and coordinated the implementation of the project.

Contributors JZ performed the literature review, data analysis and interpretation of findings and drafted the manuscript. WJZ, YS and QXZ conceived the study and participated in its design and coordination. YYM, ANC, XPZ and QXZ participated in the investigation. QXZ contributed to the interpretation of findings and revision of the paper. All authors have read and approved the final version of the manuscript and agree with the order of presentation of the authors.

Funding This study was funded by Shanghai Municipal Commission of Health and Family Planning (2012-LG-02) and National Science and Technology Basic Work Program of China (2013FY110500).

Competing interests None declared.

Patient consent for publication Not required.

Ethics approval This study has been approved by the Institutional Review Board of Shanghai Institute of Planned Parenthood Research.

Provenance and peer review Not commissioned; externally peer reviewed.

Data availability statement No additional data are available.

Open access This is an open access article distributed in accordance with the Creative Commons Attribution Non Commercial (CC BY-NC 4.0) license, which permits others to distribute, remix, adapt, build upon this work non-commercially, and license their derivative works on different terms, provided the original work is properly cited, appropriate credit is given, any changes made indicated, and the use is non-commercial. See: http:// creativecommons.org/licenses/by-nc/4.0/. 


\section{REFERENCES}

1. National Bureau of Statistics of China. National statistical bulletin on economy and society by 2015 . Available: www.stats.gov.cn/tjsj/zxfb/ 201602/t20160229_1323991.html [Accessed 13 Jul 2016].

2. National Bureau of Statistics of China. National data of registered population in Shanghai by 2014. Available: http://data.stats.gov.cn/ easyquery.htm?cn=E0105\&zb=A02\&reg=310000\&s]=2014 [Accessed 25 Jun 2016].

3. National Bureau of Statistics of China. National data of residents in Shanghai by 2014. Available: http://data.stats.gov.cn/easyquery. htm?cn=E0103\&zb=A0301\&reg=310000\&s]=2014 [Accessed 25 Jun 2016].

4. National Health Commission of the People's Republic of China. Report on development of floating population in China 2018, 2019. Available: http://shs.ndrc.gov.cn/shfzdt/201812/t20181226_923630. html [Accessed 21 Feb 2019].

5. Bartlett H, Phillips DR. Ageing and aged care in the people's Republic of China: national and local issues and perspectives. Health Place 1997;3:149-59.

6. National Bureau of Statistics of China. China's old-age dependency ratio in 2010-2014. Available: http://data.stats.gov.cn/easyquery. htm?cn=C01 [Accessed 21 Aug 2016].

7. He C, Ye J. Lonely sunsets: impacts of rural-urban migration on the left-behind elderly in rural China. Popul Space Place 2014;20:352-69.

8. Bradley DE, Longino CF, Stoller EP, et al. Actuation of mobility intentions among the young-old: an event-history analysis. Gerontologist 2008;48:190-202.

9. Erickson LD, Call VRA, Brown RB. SOS-satisfied or stuck, why older rural residents stay put: aging in place or stuck in place in rural Utah*. Rural Sociol 2012;77:408-34.

10. Evandrou M, Falkingham J, Green M. Migration in later life: evidence from the British household panel study. Popul Trends 2010;141:77-94.

11. Brown DL, Bolender BC, Kulcsar LJ, et al. Intercounty variability of net migration at older ages as a path-dependent process. Rural Sociol 2011;76:44-73.

12. Dou X, Liu Y. Elderly migration in China: types, patterns, and determinants. J App/ Gerontol 2017;36:751-71.

13. Petkoska J, Earl JK. Understanding the influence of demographic and psychological variables on retirement planning. Psychol Aging 2009;24:245-51.

14. Stoller EP, Longino CF. 'Going home' or 'leaving home'? the impact of person and place ties on anticipated counterstream migration. Gerontologist 2001;41:96-102.

15. Ma A, Chow NWS. Determinants of elderly residential mobility in southern China: exploration and implications. Ageing Int 2006;31:59-70.

16. Frey WH, Liaw K-L, Lin G. State magnets for different elderly migrant types in the United States. Int J Popul Geogr 2000;6:21-44.

17. Clark WAV, Lisowski W. Examining the life course sequence of intending to move and moving. Popul Space Place 2018;24:e2100.

18. Longino CF, Perzynski AT, Stoller EP. Pandora's briefcase: Unpacking the retirement migration decision. Res Aging 2002;24:29-49.

19. Longino CF, Bradley DE, Stoller EP, et al. Predictors of non-local moves among older adults: a prospective study. J Gerontol B Psychol Sci Soc Sci 2008;63:S7-S14.
20. Kristiansen M, Kessing LL, Norredam M, et al. Migrants' perceptions of aging in Denmark and attitudes towards remigration: findings from a qualitative study. BMC Health Serv Res 2015;15:225.

21. National Bureau of Statistics of China. Regions of Western, eastern, central and northeastern China. Available: http://www.stats.gov.cn/ ztjc/zthd/sjtjr/dejtjkfr/tjkp/201106/t20110613_71947.htm [Accessed 11 May 2019].

22. Ministry of Civil Affairs of the People's Republic of China. Ministry of civil affairs of China actively promotes the private participation in the aged care service industry. Available: http://www.mca.gov.cn/article/ xw/mzyw/201605/20160515000681.shtml [Accessed 11 May 2019].

23. The Central People's Government of China. Opinions of the state council of China on accelerating the development of the aged care service industry. Available: http://www.gov.cn/zwgk/2013-09/13/ content 2487704.htm [Accessed 11 May 2019].

24. Asia for Educators, Columbia University. Chinese geography: readings and maps. Available: http://afe.easia.columbia.edu/china/ geog/maps.htm\#4b [Accessed 23 Aug 2016].

25. The State Council of China. Opinions of the state council on further promoting the reform of the household registration system. Available: http://www.gov.cn/zhengce/content/2014-07/30/content_8944.htm [Accessed 20 Feb 2019].

26. Zhang J, Lin S, Liang D, et al. Public health services utilization and its determinants among internal migrants in China: evidence from a nationally representative survey. Int $J$ Environ Res Public Health 2017;14:1002.

27. Reijneveld SA. Reported health, lifestyles, and use of health care of first generation immigrants in the Netherlands: do socioeconomic factors explain their adverse position? J Epidemiol Community Health 1998;52:298-304.

28. Carlson JE, Junk VW, Fox LK, et al. Factors affecting retirement migration to Idaho: an adaptation of the amenity retirement migration model. Gerontologist 1998;38:18-24.

29. Shao-long W, Li L. Three issues of migrants' health insurance in China. Chin J Health Policy 2012;5:30-6. [article in chinese].

30. The State Council of China. Presidential order of the peoples' Republic of China, No.35, 2019. Available: http://www.gov.cn/flfg/ 2010-10/28/content_1732964.htm [Accessed 20 Feb 2019].

31. Wei S. Social security, propping up a 'protective umbrella' for the floating population, 2019. Available: http://www.npc.gov.cn/npc/ xinwen/lfgz/lfdt/2011-07/13/content_1663277_2.htm [Accessed 20 Feb 2019].

32. Haishan J. Research on medical insurance and medical service utilization status among internal migrants - based on national monitoring data. World Surv Res 2016;(07):14-20. [article in chinese].

33. Amcoff $\mathrm{J}$ T. Why return migrants return: survey evidence on motives for internal return migration in Sweden. Popul Space Place 2011;17:656-73.

34. Stringhini S, Berkman L, Dugravot A, et al. Socioeconomic status, structural and functional measures of social support, and mortality: the British Whitehall II cohort study, 1985-2009. Am J Epidemiol 2012;175:1275-83.

35. Hou Z, Lin S, Zhang D. Social capital, neighbourhood characteristics and utilisation of local public health services among domestic migrants in China: a cross-sectional study. BMJ Open 2017;7:e14224.

36. Norredam $\mathrm{M}$, Hansen $\mathrm{OH}$, Petersen $\mathrm{JH}$, et al. Remigration of migrants with severe disease: myth or reality?a register-based cohort study. Eur J Public Health 2015;25:84-9. 